\title{
Analisis Metode Lintasan Feynman pada Interferensi 1, 2, 3, dan 4 Celah
}

\author{
Mahendra Satria Hadiningrat, ${ }^{*}$ Endarko, ${ }^{\dagger}$ dan Bintoro Anang Subagyo ${ }^{\ddagger}$ \\ Jurusan Fisika, Fakultas Matematika dan Ilmu Pengetahuan Alam, \\ Institut Teknologi Sepuluh Nopember (ITS), Kampus ITS Sukolilo, Surabaya 60111
}

Intisari

\begin{abstract}
Pada paper ini dijelaskan secara rinci analisis gangguan pada 1,2,3 dan 4 celah yang didasarkan pada metode lintasan Feynman dalam pendekatan difraksi Fraunhofer. Formulasi pendekatan difraksi Fraunhoffer sulit untuk mendapatkan, sehingga didesain dengan mengaplikasikan prinsip aksi klasik sebagai dasar formulasi awal. Hal ini digunakan untuk menghitung distribusi probabilitas elektron yang melalui celah akibat model gangguan yang terdeteksi di layar dan dinyatakan dalam bentuk grafik.
\end{abstract}

Abstract

It had been explained in analytical detail of interference on 1, 2, 3 and 4 slits which is based on Feynman Path Method within the Fraunhofer diffraction approachment. Those formulas are difficult to derive, thereafter, in simply design being applicated on classical action principle as a basic of deriving formula. It is used to compute probability distribution of electron through those slits as a result of interference model which is detected on a screen and represented on graph.

KATA KUNCI: Fraunhofer diffraction, Feynman path method.

\section{PENDAHULUAN}

Thomas Young (1773-1829) menunjukkan eksperimen terkenalnya yaitu difraksi celah ganda menggunakan sumber cahaya monokromatik, yang masuk melalui 2 celah sempit dan diteruskan sampai ke layar. Eksperimen tersebut memperlihatkan pola interferensi (terang-gelap) pada layar. Efek interferensi ini dijelaskan dalam kerangka optika fisis melalui prinsip Huygens-Fresnel. Prinsip ini memberikan penjelasan detail tentang proses difraksi, dengan tiap celah diterapkan penjalaran gelombang sferis. Konsep mekanika kuantum untuk mendeskripsikan eksperimen ini, salah satunya adalah fenomena perjalanan partikel terhambur, misalnya elektron atau foton. Untuk tinjauan kuantum, yang terlintas adalah seberapa besar probabilitas partikel yang terhitung melalui 2 celah sebagai hasil dari pola interferensi yang terdeteksi pada layar. Dasar untuk menjawab pertanyaan tersebut adalah dengan metode lintasan Feynman [1]. Set eksperimen yang berhubungan dengan terhamburnya partikel adalah fenomena interferensi celah ganda seperti ditunjukkan Gambar 1.

Partikel terhambur di $\mathrm{O}$ sebelum mencapai detector di y yang bergerak sampai ke layar $\mathrm{C}$, partikel bergerak melalui celah 1 dan 2 dengan asumsi sebagai berikut:

- Jika celah 2 ditutup, partikel hanya melewati celah 1

\footnotetext{
*E-MAIL: mahendrasatriahadiningrateyahoo.com

${ }^{\dagger}$ E-MAIL: endarko@gmail.com

‡E-MAIL: b_anang@physics.its.ac.id
}

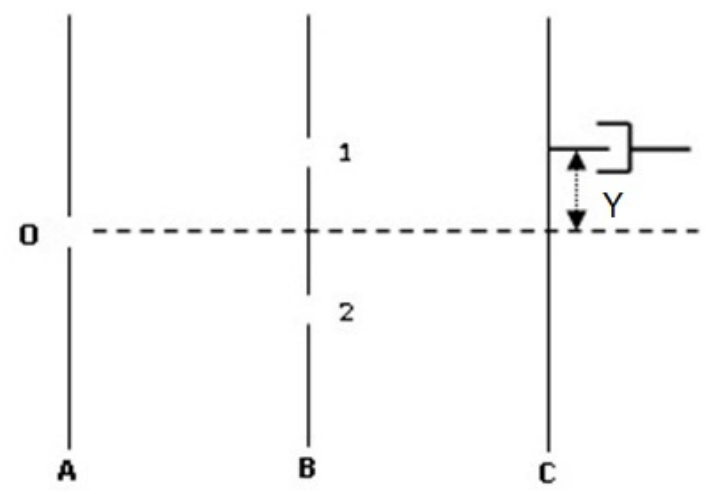

Gambar 1: Set eksperimen interferensi celah ganda.

maka distribusi probabilitas partikel yang tercatat pada layar C adalah P1 (Gambar 2(a)),

- Jika celah 1 ditutup, partikel hanya melewati celah 2, maka distribusi probabilitas partikel yang tercatat pada layar C adalah P2 (Gambar 2(b)).

dari pernyataan di atas bahwa jika celah 1 dan 2 dibuka bersamaan maka distribusi probabilitas partikel pada layar $\mathrm{C}$ merupakan jumlahan $\mathrm{P}=\mathrm{P} 1+\mathrm{P} 2$ dan membentuk kurva seperti Gambar 2(c).

Namun, kenyataan secara eksperimen yang teramati tidak demikian $\mathrm{P} \neq(\mathrm{P} 1+\mathrm{P} 2)$, melainkan terdapat fluktuasi dari distribusi partikel yang tertangkap di detektor pada layar C. Fenomena ini menunjukkan bahwa trayektori partikel dari sumber $\mathrm{O}$ menuju detektor mempunyai banyak (alternatif) 


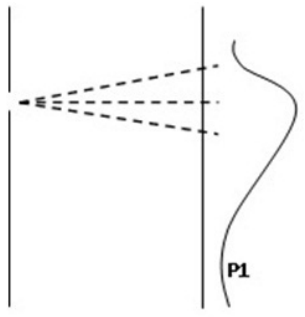

(a)

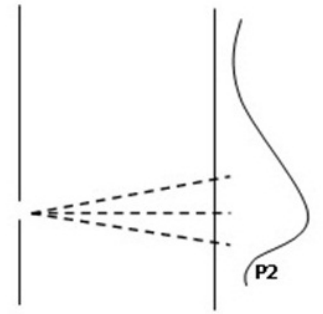

(b)

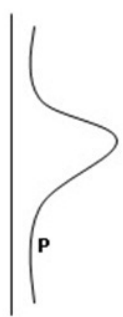

(c)
Gambar 2: Distribusi probabilitas kehadiran partikel di detektor y pada layar $\mathrm{C}$.

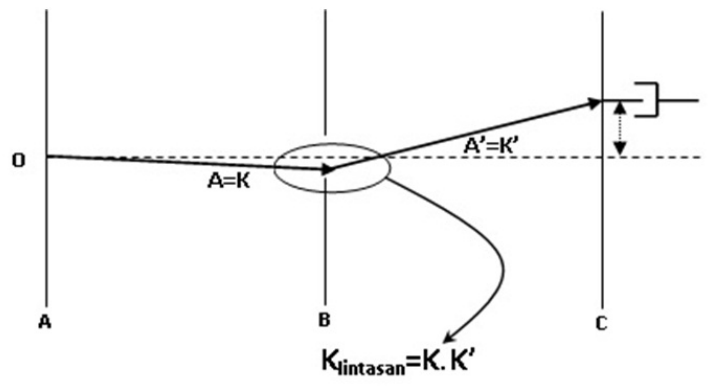

Gambar 3: Lintasan partikel pada eksperimen 1 celah.

lintasan seperti pada Gambar 3, bahkan ada yang bergerak zig-zag diantara layar A dan B sebelum mencapai layar C. Lintasan-lintasan inilah yang menggugah inspirasi Feynman untuk mempermudah formulasi pendahulunya dan bermakna lebih fisis. Konsep ini sangat menarik karena menganalisis alternatif lintasan/ perjalanan partikel yang mungkin dan distribusi probabilitas partikel sebagai pembentuk pola interferensi [1].

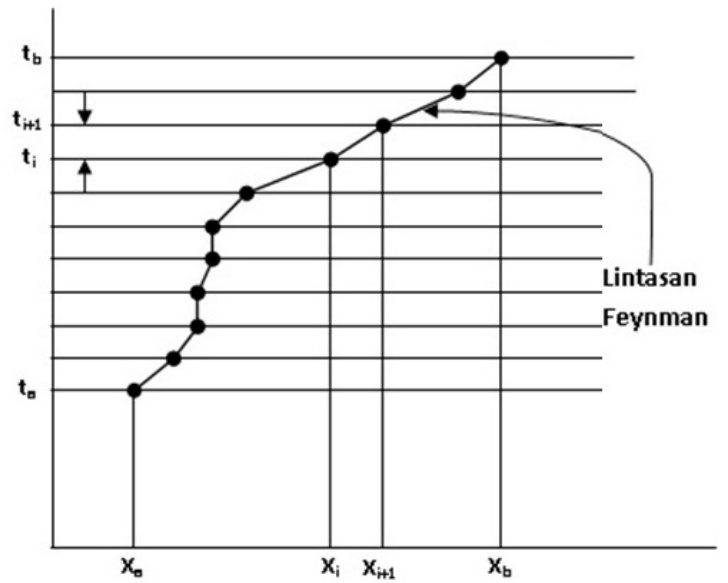

Gambar 4: Plot waktu terhadap posisi, integral lintasan partikel bergerak dari posisi $\mathrm{x}_{a}$ ke $\mathrm{x}_{b}$, interval waktu dari $\mathrm{t}_{a}$ ke $\mathrm{t}_{b}$ dengan batasan waktu $\epsilon \rightarrow 0$.

\section{FORMULASI FEYMAN}

Integral lintasan Feynman adalah kerangka untuk memformulasikan teori kuantum. Teori integral tersebut dikembangkan pertama kali oleh P.A.M Dirac (1933) dan R.P Feynman (1948). Integral lintas merupakan dasar untuk menjelaskan teori kuantum, perumusan terakhir integral lintas sangat sederhana namun proses penurunan membutuhkan matematika rumit. Untuk menghindari permasalahan tersebut, diaplikasikan metode analisis fungsional karena kuantitas fundamental berdasarkan komutasi dari pada operator aljabar dan didasarkan pada Prinsip Aksi Klasik. Dari metode inilah aturan Feynman dapat disederhanakan dengan mudah [2].

Jika partikel berada di posisi $\mathrm{x}_{a}$, waktu $\mathrm{t}_{a}$ dan di $\mathrm{x}_{b}$, waktu $\mathrm{t}_{b}\left(\mathrm{t}_{b}>\mathrm{t}_{a}\right)$ diberikan Prinsip Aksi melalui pendekatan klasik bernilai minimum

$$
\frac{\delta}{\delta x(t)} S\left[x_{b}, t_{b} ; x_{a}, t_{a}\right]_{x, \text { partikel }}=0
$$

dengan

$$
S\left[x_{b}, t_{b} ; x_{a}, t_{a}\right] \equiv \int^{t_{f}} L[x(t), \dot{x}(t), t] d t
$$

Konsep probabilitas dalam mekanika kuantum menggunakan prinsip superposisi, yang diartikan sebagai probabilitas total atau jumlahan semua probabilitas yang mungkin untuk tiap lintasan yang berbeda. Untuk tiap satu lintasan kecil (m - n) berada diantara titik $\mathrm{x}_{i}$ dan $\mathrm{x}_{i+1}$ dengan interval waktu $\epsilon$ $=\mathrm{t}_{(i+1)} \mathrm{t}_{i}($ Gambar 4$)$, dan proses ini dapat dilakukan dengan tak hingga/ alternatif lintasan yang mungkin, lintasan inilah yang menggugah inspirasi Feynman untuk menghitung formula integral lintasan (Gambar 3). Dari Prinsip Aksi di atas, diberikan jumlahan dari tiap aksi (lintasan kecil $\mathrm{m}$ - n) untuk satu lintasan dari posisi $\mathrm{x}_{a}$ ke $\mathrm{x}_{b}($ Gambar 4), 


$$
S\left[x_{b}, t_{b} ; x_{a}, t_{a}\right]=\sum_{i}\left\{\frac{m}{2} \frac{\left(x_{i+1}-x_{i}\right)^{2}}{\epsilon}-\epsilon V\left(\frac{x_{i+1}+x_{i}}{2}\right)\right\}
$$

Tampak dalam Gambar 4, bahwa seluruh alternatif lintasan dapat diartikan sebagai amplitudo (Kernel (K)) untuk partikel yang bergerak dari posisi $\mathrm{x}_{a}$ waktu $\mathrm{t}_{a}$ ke posisi $\mathrm{x}_{b}$ waktu $\mathrm{t}_{b}$ atau perkalian amplitudo dari masing-masing lintasan $\mathrm{m}-\mathrm{n}$ diberikan oleh

$$
K \approx \epsilon \rightarrow 0 \frac{1}{\text { const }} \iint \cdots \int e^{\frac{i}{\hbar} S[x(t)]} \frac{d x_{1}}{\text { const }} \cdots \frac{d x_{n-1}}{\text { const }}
$$

Untuk lebih mudah memahami formula secara riil, diberikan set eksperimen interferensi menggunakan 1 celah (Gambar 3). Dalam konsep mekanika kuantum, amplitudo lintasan total untuk 1 celah sama dengan perkalian amplitudo (K) dan (K')

$$
K\left[x_{b}, t_{b} ; x_{a}, t_{a}\right]=\lim _{\epsilon \rightarrow 0, n \rightarrow \infty} \frac{1}{(2 i \pi \hbar \epsilon / m)^{1 / 2}} \int \frac{d x_{1}}{(2 i \pi \hbar \epsilon / m)^{1 / 2}} \int \frac{d x_{2}}{(2 i \pi \hbar \epsilon / m)^{1 / 2}} \exp \left(\frac{i}{\hbar} \frac{m\left(x_{2}-x_{1}\right)^{2}}{2 \epsilon}\right)
$$

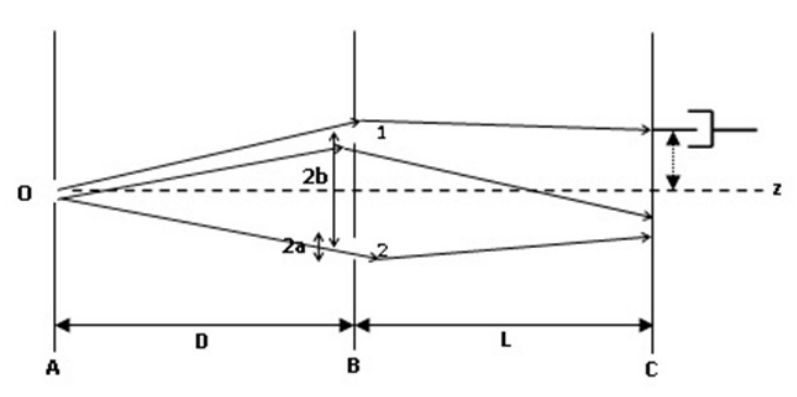

Gambar 5: Lintasan partikel eksperimen 2 celah.

\section{DISTRIBUSI PROBABILITAS DALAM SUKU INTEGRAL FRESNEL}

Dalam konsep mekanika kuantum, dikarenakan ukuran lintasan partikel tidak dapat diketahui secara pasti, maka tidak dapat diketahui ketika partikel bergerak melalui celah. Sangat mungkin partikel bergerak melalui celah dalam beberapa kali sebelum sampai di layar, dan probabilitasnya relatif kecil sehingga solusinya diberikan batasan jarak dari sumber ke celah dan dari celah ke layar pada set eksperimen (Gambar 5) dengan jarak antar kedua celah (2b) dan lebar kedua celah (2a), partikel terhambur dari sumber ke celah selama waktu T dan dari celah ke layar selama waktu $\tau$. Probabilitas amplitudo partikel dapat dihitung dari sumber saat posisi awal $\mathrm{O}=$ $(\mathrm{x}, \mathrm{y}, \mathrm{z})=(0,0,0)$ dengan waktu $\mathrm{t}=0$ menuju ke layar dan saat di posisi akhir $(\mathrm{x}, \mathrm{z}=\mathrm{D}+\mathrm{L})$ dengan waktu $\mathrm{T}+\tau$, untuk posisi di titik pusat antar kedua celah $(\mathrm{w}, \mathrm{z}=\mathrm{D}),-\mathrm{b}<\mathrm{w}<$ b dengan waktu $\mathrm{t}=\mathrm{T}$. Pernyataan ini hanya bisa diasumsikan sesuai pandangan klasik. Diasumsikan panjang gelombang $\lambda$, yang besarnya mendekati atau sama dengan panjang gelombang arah $\mathrm{z}, \lambda_{z}=2 \pi \hbar /\left(\mathrm{mv}_{z}\right)$ namun lebih kecil dibandingkan jarak $\lambda<<\mathrm{D}$, L.

Proses berikutnya menghitung amplitudo transisi partikel bergerak dari titik $\mathrm{O}=(\mathrm{x}, \mathrm{y}, \mathrm{z})=(0,0,0)$ saat waktu $\mathrm{t}=0$, melalui 2 celah di posisi $(\mathrm{w}, \mathrm{z}=\mathrm{D}),-\mathrm{b}<\mathrm{w}<\mathrm{b}$ saat waktu $\mathrm{t}=\mathrm{T}$ dan tiba (layar c) di posisi $(\mathrm{x}, \mathrm{z}=\mathrm{L}+\mathrm{D})$ saat waktu $\mathrm{t}=\mathrm{T}+\tau$. Kemudian menghitung amplitudo $\mathrm{A}_{1}(\mathrm{z}), \mathrm{A}_{2}(\mathrm{z})$ yang keluar dari masing-masing celah 1 dan 2, kemudian 2 amplitudo tersebut ditambah untuk memperoleh amplitudo total $\mathrm{A}(\mathrm{z})$ dan di modulus kuadratkan, didapatkan probabilitas

$$
P(z) \equiv|A(z)|^{2}
$$

Ekspresi persamaan untuk $\mathrm{A}_{1}(\mathrm{z})$ adalah

$$
A_{1}(x, a, b)=\int_{-b}^{b} d \omega \frac{e^{i \frac{m(x-\omega)^{2}}{2 \hbar \tau}}}{\sqrt{2 i \pi \hbar \tau / m}} \frac{e^{i \frac{m \omega^{2}}{2 \hbar T}}}{\sqrt{2 i \pi \hbar T / m}}
$$

lebih lanjut disederhanakan,

$$
A_{1}(x, a, b)=\frac{e^{i \frac{m x^{2}}{2 \hbar(T+\tau)}}}{\sqrt{(2 i)^{2} \pi \hbar(T+\tau) / m}} \int_{\alpha_{-}^{(1)}}^{\alpha_{+}^{(1)}} d \omega \exp \left(\frac{i \pi}{2} \omega^{2}\right)(8)
$$

Kemudian didapatkan ekspresi analitik untuk amplitudo

$$
A_{1}(x, a, b)=\frac{e^{i \frac{m x^{2}}{2 \hbar(T+\tau)}}}{\sqrt{(2 i)^{2} \pi \hbar(T+\tau) / m}} \times\left(C\left[\alpha_{+}(x, a, b)\right]-C\left[\alpha_{-}(x, a, b)\right]+i S\left[\alpha_{+}(x, a, b)\right]-i S\left[\alpha_{-}(x, a, b)\right]\right)
$$

Sehingga didapatkan distribusi probabilitas untuk 1 celah adalah

$$
P(x ; a)=\frac{1}{2 \lambda(L+D)}\left(\left[C\left(\alpha_{+}(x, a, b)\right)+C\left(\alpha_{-}(x, a, b)\right)\right]^{2}-\left[S\left(\alpha_{+}(x, a, b)\right)+S\left(\alpha_{-}(x, a, b)\right)\right]^{2}\right)
$$




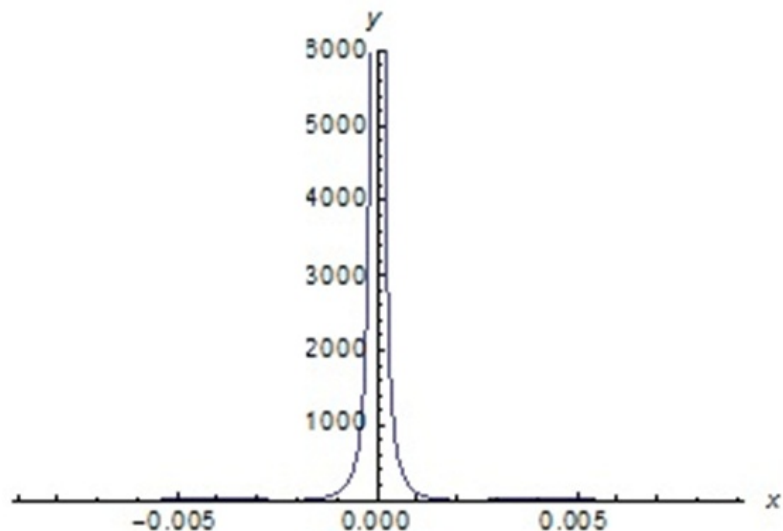

(a) Intensitas 1 celah

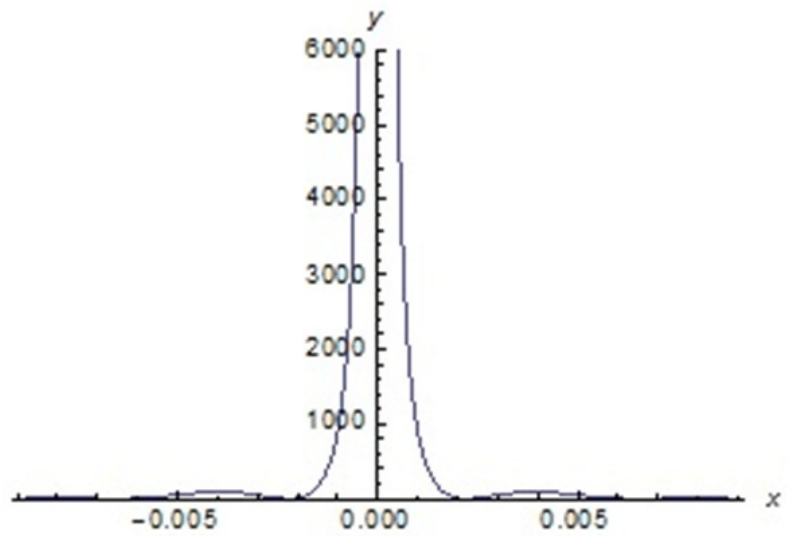

(c) Intensitas 3 celah

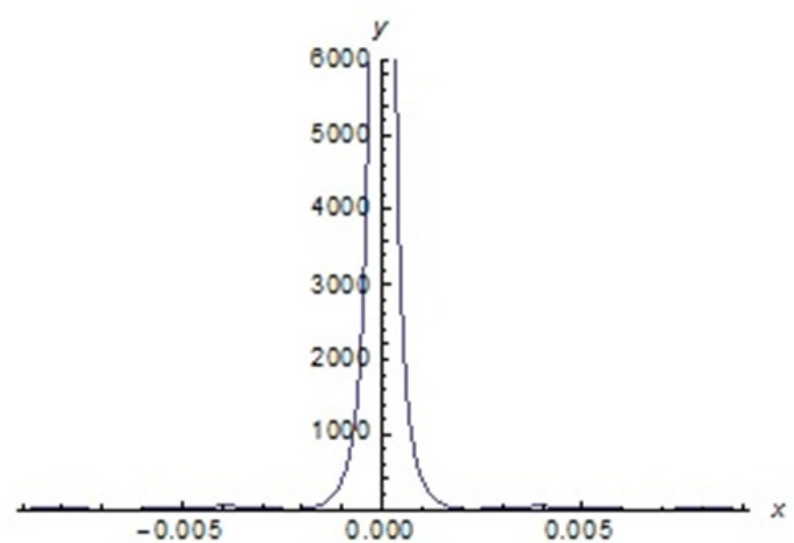

(b) Intensitas 2 celah

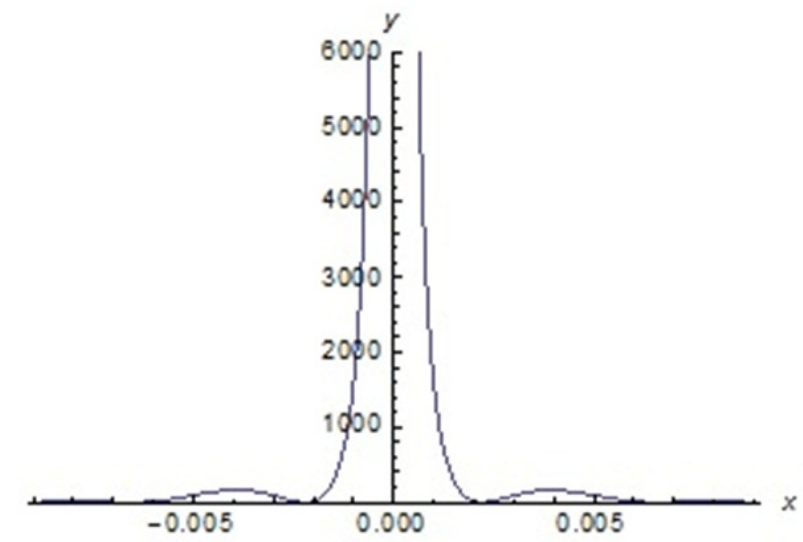

(d) Intensitas 4 celah

Gambar 6: Intensitas pola medan jauh.

dengan menggunakan parameter $\eta=1+\mathrm{L} / \mathrm{D}$ dan $\gamma=\eta-1$ maka diperoleh distribusi probabilitas untuk 1 celah dengan nilai NF $($ medan jauh $)=0,01($ Gambar 6 (a)) [3],

$$
P(x ; a) \approx \frac{2 \gamma}{\pi^{2} \eta^{2}}\left(\frac{a^{2}}{\left(\frac{x^{2}}{\eta^{2}}-a^{2}\right)^{2}}+\frac{1}{\frac{x^{2}}{\eta^{2}}-a^{2}} \sin ^{2}\left(\pi N_{F}(a) \frac{x}{a}\right)\right)
$$

\section{HASIL DAN PEMBAHASAN}

Probabilitas 2 celah dapat ditentukan dengan persamaan:

$$
\begin{aligned}
P^{2 \text { celah }}(x, a, b) & =P_{1}(x, a, b)+P_{2}(x, a, b)+I_{12}(x, a, b) \\
& =\frac{16}{\pi^{2}} \frac{1}{N_{F} \eta\left(1-\frac{x}{a \eta}\right)^{2}} \cos ^{2}\left(\frac{\pi}{2} N_{F} \eta\left(1-\frac{x}{1 \eta}\right)^{2}\right)
\end{aligned}
$$

menggunakan konsep yang sama, maka hasil yang diperoleh juga sama hanya berbeda konstanta [4]. Berikut distribusi probabilitas untuk $\mathrm{N}=3$, dan 4 celah, 


$$
\begin{aligned}
P^{3 \text { celah }}(x, a, b) & =\frac{36}{\pi^{2}} \frac{1}{N_{F} \eta\left(1-\frac{x}{a \eta}\right)^{2}} \cos ^{2}\left(\frac{\pi}{2} N_{F} \eta\left(1-\frac{x}{1 \eta}\right)^{2}\right) \\
P^{4 \text { celah }}(x, a, b) & =\frac{64}{\pi^{2}} \frac{1}{N_{F} \eta\left(1-\frac{x}{a \eta}\right)^{2}} \cos ^{2}\left(\frac{\pi}{2} N_{F} \eta\left(1-\frac{x}{1 \eta}\right)^{2}\right)
\end{aligned}
$$

dengan grafik intensitas pola medan jauh untuk 2, 3, dan 4 celah ditunjukkan Gambar 6.

\section{SIMPULAN}

1. Jika nilai $\mathrm{N}_{F}$ pada persamaan distribusi probabilitas tidak dihitung, maka representasi grafik yang muncul dari metode Feynman yaitu pada nilai amplitudo dari titik pusat (terang), titik ke-dua (gelap) dan seterusnya selalu sama;

2. Jika nilai $\mathrm{N}_{F}$ pada persamaan distribusi probabilitas berubah-ubah, maka representasi grafik yang muncul dari metode Feynman yaitu fluktuaktif (nilai amplitudo tidak sama) dari titik pusat (terang), titik ke-dua (gelap) dan seterusnya;

3. Semakin kecil lebar celah, maka semakin besar lebar penyebarannya;

4. Semakin banyak jumlah celah, maka semakin besar nilai amplitudonya di titik pusat (terang).
[1] R.P. Feynman, R.B. Leighton, and M.L. Sands, The Feynman Lectures on Physics (Addison-Wesley, Reading, MA, 1963).

[2] R.P. Feynman, A.R. Hibbs, Quantum Mechanics and Path Integral (Addison-Wesley, Reading, MA, 1965).
[3] M. Beau, Feynman Integral and one/two slits electrons diffraction:an analytic study, arXiv:1110.2346v2/EJP, 2012

[4] R. Sawant, et all., Phys. Rev. Lett., 113, 120406 (2014). 